\title{
Role of interleukin-1 receptor 1/MyD88 signalling in the development and progression of pulmonary hypertension
}

\author{
Aurélien Parpaleix ${ }^{1}$, Valérie Amsellem ${ }^{1}$, Amal Houssaini ${ }^{1}$, Shariq Abid ${ }^{1}$, \\ Marielle Breau ${ }^{1}$, Elisabeth Marcos ${ }^{1}$, Daigo Sawaki ${ }^{1}$, Marion Delcroix ${ }^{2}$, \\ Rozenn Quarck², Aurélie Maillard ${ }^{3}$, Isabelle Couillin ${ }^{3}$, Bernhard Ryffel ${ }^{3}$ and \\ Serge Adnot ${ }^{1}$
}

\begin{abstract}
Affiliations: ' ${ }^{1}$ NSERM U955 and Département de Physiologie, Hôpital Henri Mondor, AP-HP, DHU-ATVB, F-94010, Université Paris-Est Créteil (UPEC), Créteil, France. ${ }^{2}$ Respiratory Division, University Hospitals of Leuven and Department of Clinical and Experimental Medicine, University of Leuven, Leuven, Belgium. ${ }^{3}$ UMR7355, INEM Centre National de la Recherche Scientifique and Université F-45071 Orleans, Orleans, France.
\end{abstract}

Correspondence: Serge Adnot, Hôpital Henri Mondor, Service de Physiologie-Explorations Fonctionnelles, 94010, Créteil, France. E-mail: serge.adnotđinserm.fr

ABSTRACT Pulmonary artery smooth muscle cell (PA-SMC) proliferation and inflammation are key components of pulmonary arterial hypertension (PAH). Interleukin (IL)-1 $\beta$ binds to IL-1 receptor (R) 1 , thereby recruiting the molecular adaptor myeloid differentiation primary response protein 88 (MyD88) (involved in IL-1R1 and Toll-like receptor signal transduction) and inducing IL-1, IL-6 and tumour necrosis factor- $\alpha$ synthesis through nuclear factor- $\kappa \mathrm{B}$ activation.

We investigated the IL-1R1/MyD88 pathway in the pathogenesis of pulmonary hypertension.

Marked IL-1R1 and MyD88 expression with predominant PA-SMC immunostaining was found in lungs from patients with idiopathic PAH, mice with hypoxia-induced pulmonary hypertension and SM22-5-HTT ${ }^{+}$ mice. Elevations in lung IL-1 $\beta$, IL-1R1, MyD88 and IL-6 preceded pulmonary hypertension in hypoxic mice. IL-1R1 $1^{-/-}$, MyD88 ${ }^{-/-}$and control mice given the IL-1R1 antagonist anakinra were protected similarly against hypoxic pulmonary hypertension and perivascular macrophage recruitment. Anakinra reversed pulmonary hypertension partially in SM22-5- $\mathrm{HTT}^{+}$mice and markedly in monocrotaline-treated rats. IL- $1 \beta$ mediated stimulation of mouse PA-SMC growth was abolished by anakinra and absent in IL- $1 \mathrm{R} 1^{-1-}$ and $\mathrm{MyD}_{8} 8^{-/-}$mice. Gene deletion confined to the myeloid lineage (M.lys-Cre MyD88 ${ }^{\mathrm{fl} / \mathrm{fl}}$ mice) decreased pulmonary hypertension severity versus controls, suggesting IL-1 $\beta$-mediated effects on PA-SMCs and macrophages. The growth-promoting effect of media conditioned by M1 or M2 macrophages from M.lysCre MyD88 $8^{\mathrm{fl} / \mathrm{fl}}$ mice was attenuated.

Pulmonary vessel remodelling and inflammation during pulmonary hypertension require IL-1R1/MyD88 signalling. Targeting the IL-1ß/IL-1R1 pathway may hold promise for treating human PAH.

@ERSpublications

The IL-1R1/MyD88 pathway is a treatment target for pulmonary arterial hypertension http://ow.ly/1Fpe3008RLs

Editorial comment in: Eur Respir J 2016; 48: 305-307.

This article has supplementary material available from erj.ersjournals.com

Received: Aug 312015 | Accepted after revision: May 32016 | First published online: July 132016

Support statement: This study was supported by grants from the INSERM and Ministère de la Recherche, Chancellerie des Universités de Paris. The UMR7355 received support for the generation of tissue-specific MyD88-deficient mice from the regional centre, FRM (Fondation pour la Recherche Médicale).

Conflict of interest: None declared.

Copyright OERS 2016 


\section{Introduction}

Chronic inflammation has been identified as a characteristic feature of various forms of pulmonary hypertension, including human pulmonary arterial hypertension (PAH) [1-4]. However, the connection between pulmonary hypertension and inflammation is poorly understood. Inflammation may occur as a secondary event during the course of pulmonary hypertension, due to the ability of proliferating pulmonary vessel cells to secrete inflammatory mediators and generate an inflammatory microenvironment [5-7]. In animal models of pulmonary hypertension, inflammation precedes vascular remodelling, suggesting that altered immunity may be a primary event during the development of pulmonary hypertension [8]. The complex processes that initiate inflammation in non-infectious conditions involve pattern-recognition receptors such as cytoplasmic nucleotide oligomerization domain (NOD)-like receptors, which assemble into high molecular-weight molecular platforms called inflammasomes and into membrane-bound Toll-like receptors (TLRs) [9]. One consequence of TLR signalling is the activation of the transcription factor nuclear factor (NF)- $\kappa \mathrm{B}$, which triggers the production of interleukin (IL)- $1 \beta$, tumour necrosis factor- $\alpha$, and IL-6 [10]. Inflammasomes, through the activation of pro-inflammatory caspases, in particular caspase- 1 , lead to the maturation and secretion of IL-1 $\beta$ and IL-18 [11]. As a major player in the complex processes involved in innate immune responses, IL-1 $\beta$ has been labelled the "gatekeeper of inflammation" $[12,13]$.

IL-1 ligands bind to a cellular receptor complex consisting of IL-1 receptor 1 (IL-1R1) and IL-1R accessory protein. The natural antagonist IL-1Ra acts by trapping IL-1R1 molecules $[14,15]$. IL-1R1 shares a common signalling pathway with most of the TLRs by recruiting the myeloid differentiation primary response protein 88 (MyD88) [16, 17], which is a critical adaptor protein in innate immunity signal transduction, leading to NF- $\kappa B$ activation $[18,19]$. This effect explains that IL-1 $\beta$ can induce its own synthesis through IL-1R1/MyD88-mediated activation of NF- $\mathrm{B}$. Thus, IL-1 $\beta$, IL-1R1 and MyD88 are key actors in the innate immune response that may occur during pulmonary hypertension and contribute to the inflammation and pulmonary vessel remodelling. However, the potential role for the IL-1R1/MyD88 pathway in pulmonary hypertension has not been specifically examined. In previous studies by our group and others [20-22], IL-1 $\beta$ was shown to act as a potent mitogenic factor on cultured pulmonary artery smooth muscle cells (PA-SMCs). Moreover, there is evidence that TLR-4 deficient mice are protected against the development of pulmonary hypertension [23] and that platelet TLR-4 activation contributes to pulmonary hypertension [24]. In rats exposed to monocrotaline, which causes lung inflammation and $\mathrm{PAH}$, the recombinant IL-1R antagonist anakinra decreased pulmonary hypertension severity [25]. Finally, improvement of PAH has been reported in a patient during anakinra therapy for adult-onset Still's disease [26].

Here, we investigated the IL-1R1/MyD88 pathway in pulmonary hypertension in several gene-deficient mouse models. Given our findings showing that IL-1R1 and MyD88 are strongly expressed in remodelled vessels from patients with idiopathic PAH (iPAH), we investigated IL-1R1 $1^{-/-}$and MyD88 ${ }^{-/-}$mice exposed to hypoxia, and we assessed the effect of anakinra on wild-type (WT) mice exposed to hypoxia; as well as on $\mathrm{SM}_{22}-5 \mathrm{HTT}^{+}$mice and on rats treated with monocrotaline. To determine whether pulmonary hypertension induction by IL-1R1 or MyD88 involved a direct effect on PA-SMCs or required macrophage activation, we studied cultured PA-SMCs and evaluated pulmonary hypertension severity in transgenic mice with $M y D 88$ gene deletion confined to the myeloid-lineage macrophages (M.lys-Cre MyD88 ${ }^{\mathrm{fl} / \mathrm{fl}}$ mice). Finally, we studied the effects of conditioned media from differentiated M1 and M2 macrophages from WT and M.lys-Cre MyD88 $8^{\mathrm{fl} / \mathrm{ll}}$ mice on the proliferation of PA-SMCs.

\section{Methods}

Collection of human tissue samples

Lung tissue was obtained from six patients with iPAH who underwent lung transplantation at the Universitaire Ziekenhuizen (Leuven, Belgium). Control lung tissue was collected from eight patients undergoing lung resection surgery for localised lung tumours at the Institut Mutualiste Montsouris (Paris, France). In each institution, the ethics committee approved the collection protocol.

\section{Animals}

All animal experiments were approved by the institutional animal care and use committee of the French National Institute of Health and Medical Research. Transgenic mice constitutively deleted for IL-1R1 $\left(\mathrm{IL}-1 \mathrm{R} 1^{-/-}\right.$) or MyD88 (MyD88 ${ }^{-/-}$) were obtained from Richard Flavell (Department of Immunobiology, School of Medicine, Yale University, New Haven, CT, USA) and Shizuo Akira (Laboratory of Host Defense, WPI Immunology Frontier Research Centre (IFReC), Osaka University, Osaka, Japan) [27, 28]. Mice with $M y D 88$ gene deletion confined to the myeloid-cell lineage (M.lys-Cre MyD88 ${ }^{\mathrm{fl} / \mathrm{fl}}$ mice) were generated on BL6 embryonic stem cells at the national scientific research centre (CNRS, UMR7355, Orleans, France). Transgenic mice with 5-hydroxytryptamine transporter (HTT) overexpression in SMCs 
$\left(\mathrm{SM}_{22}-5 \mathrm{HTT}^{+}\right.$) were produced and bred as previously described [29]. WT C57BL/6j mice and Wistar rats were obtained from Janvier (Le Genest-Saint-Isle, France).

The online supplementary material provides details of the animal studies, anakinra treatment, macrophage isolation and polarisation, PA-SMC proliferation experiments, analyses of IL-1 $\beta / \mathrm{IL}-1 \mathrm{R} 1 / \mathrm{MyD} 88$ and inflammasome pathways and statistical analysis.

\section{Results}

Increased expression of IL-1R1 and MyD88 in lungs from patients with iPAH and mice with pulmonary hypertension

In lung tissue from patients with iPAH, we found marked increases in IL-1R1 and MyD88 protein levels compared to control lung tissue (fig. 1a). Immunofluorescence staining for IL-1R1 and MyD88 predominated in PA-SMCs from the hypertrophied media of pulmonary vessels, as shown by double-immunofluorescence staining for $\alpha$-smooth muscle actin and IL-1R1 or MyD88 (fig. 1b).

In mice exposed to 21 days of hypoxia, we found substantial increases in lung IL-1R1 and MyD88 mRNA and protein levels compared with normoxic mice (fig. 2a), with predominance of IL-1R1 and MyD88 immunostaining in the PA-SMC layer of remodelled vessels (fig. 2c). We found no immunostaining for

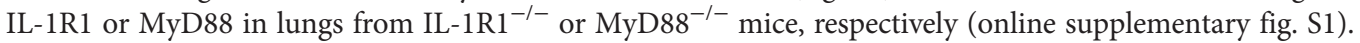
Interestingly, lung IL-1R1 and MyD88 mRNA increased early during hypoxia exposure, before pulmonary hypertension development. Lung IL-1 $\beta$ mRNA and protein levels peaked at $48 \mathrm{~h}$ then decreased, with the protein returning to control normoxic levels by day 21 (fig. $2 \mathrm{~b}$ ). IL-6 levels paralleled the IL-1 $\beta$ levels.
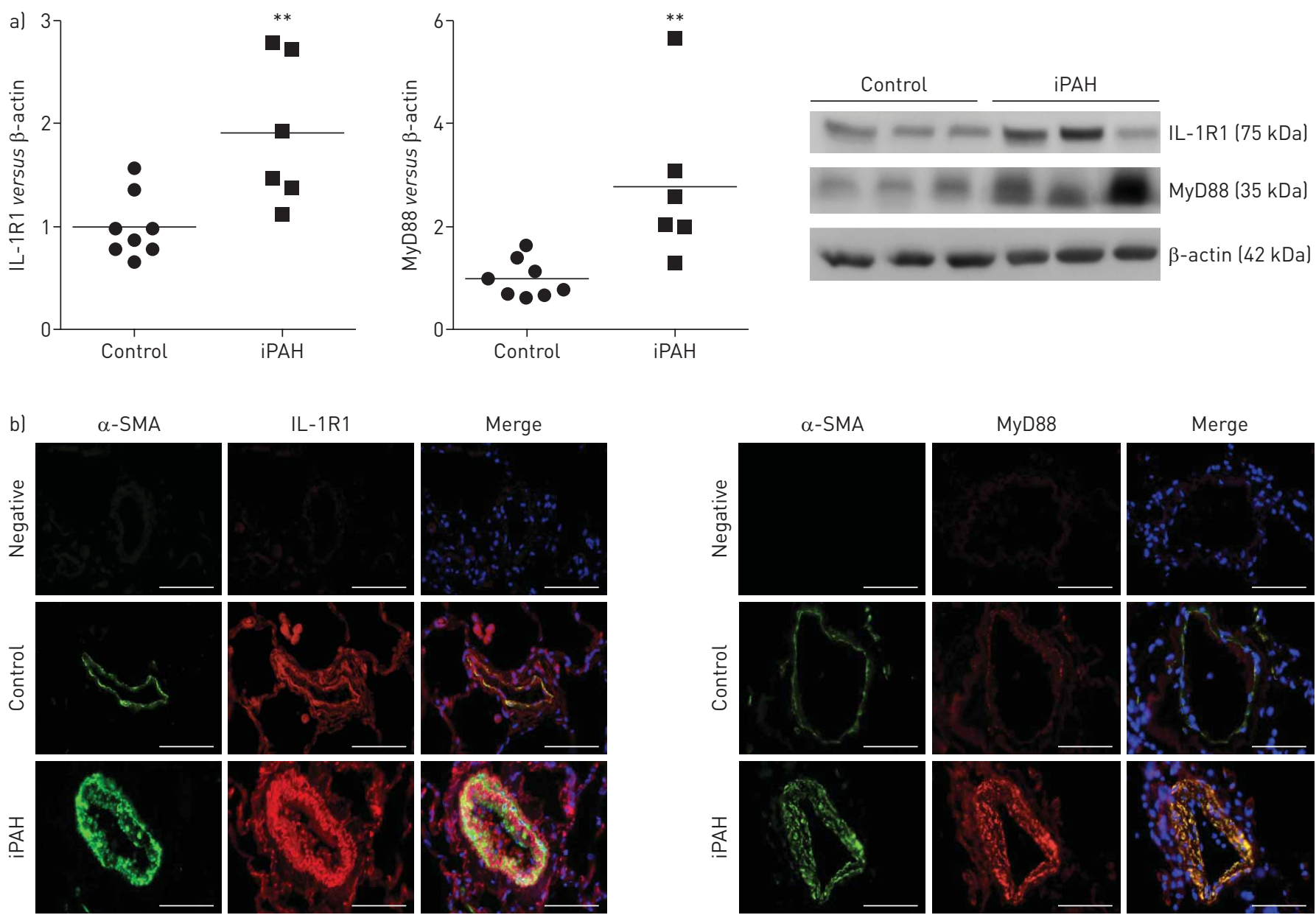

FIGURE 1 Increased expression of interleukin-1 receptor (IL-1R)1 and myeloid differentiation primary response protein 88 (MyD88) in human pulmonary arterial hypertension (PAH). a) IL-1R1 and MyD88 protein levels measured by Western blot in total lung-protein extracts from six patients with idiopathic (i)PAH and eight age- and sex-matched controls. ${ }^{* *}$ : $p<0.01$. b) IL-1R1 and MyD88 co-localise with smooth muscle cells. Representative micrographs of lung tissue from patients and controls. IL-1R1 or MyD88 (red), $\alpha$-smooth muscle actin (SMA) (green) for smooth muscle cell staining, or Hoechst dye for nucleus staining (blue). No positive immunoreactivity was detected in sections incubated with the appropriate control lgG followed by secondary anti-rabbit and anti-mouse antibodies. Scale bars=50 $\mu \mathrm{m}$. 

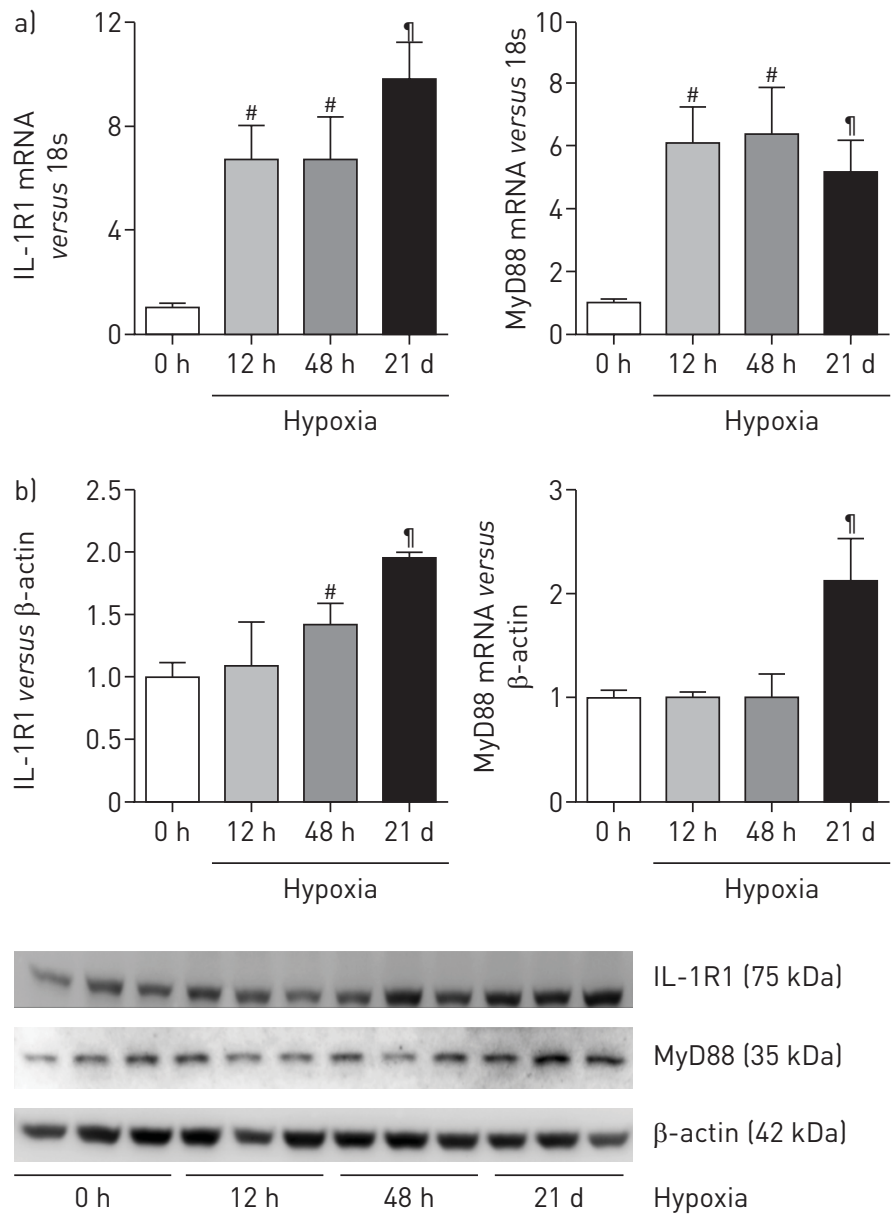

IL-1R1 (75 kDa)

MyD88 (35 kDa)

$\beta$-actin $(42 \mathrm{kDa})$

Hypoxia

c)

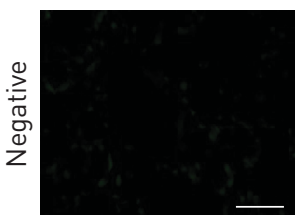

IL-1R1



FIGURE 2 Increased expression of the interleukin-1 receptor (IL-1R)1/myeloid differentiation primary response protein 88 (MyD88) pathway in murine hypoxia-induced pulmonary arterial hypertension (PAH). a) IL-1R1, MyD88, IL-1 $\beta$ and IL-6 mRNA levels measured using quantitative real-time polymerase chain reaction in lungs from mice after hypoxia exposure for various durations (12 h, $48 \mathrm{~h}$ or $21 \mathrm{days}$ (d)). b) Lung IL-1R1 and MyD88 protein levels measured using Western blot and lung IL-1 $\beta$ and IL-6 protein levels measured using ELISA after hypoxia exposure for

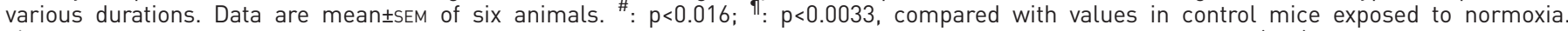
c) Representative micrographs of lung tissue from mice under normoxia and after $21 \mathrm{~d}$ of hypoxia. IL-1R1 or MyD88 (red), $\alpha$-smooth muscle actin (SMA) (green) for smooth muscle cell staining, or Hoechst for nucleus staining (blue). No immunoreactivity was detected in sections incubated with rabbit IgG control and secondary anti-rabbit antibody. Scale bars $=30 \mu \mathrm{m}$. 
Similarly, SM22-5 $\mathrm{HTT}^{+}$mice with spontaneous pulmonary hypertension exhibited increased lung IL-1R1 and MyD88 mRNA levels compared to control WT mice, despite being studied under normoxic conditions (online supplementary fig. S2A).

\section{Effects of IL-1R1 or MyD88 gene deletion and anakinra treatment on hypoxic pulmonary hypertension in mice}

After 21 days of hypoxia exposure, right ventricular (RV) systolic pressure was significantly lower and RV hypertrophy less severe in IL- $1 \mathrm{R}^{-/-}$and $\mathrm{MyD} 88^{-/-}$mice than in control WT mice (fig. 3a). Furthermore, distal pulmonary vessels were less muscular in mutant mice than in WT mice, with a smaller percentage of dividing $\mathrm{Ki}^{+} 7^{+}$pulmonary vessel cells (fig. 3b). Severity of pulmonary hypertension was not

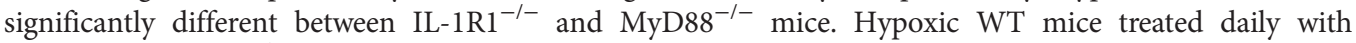
anakinra $\left(20 \mathrm{mg} \cdot \mathrm{kg}^{-1}\right)$ exhibited a similar degree of protection against pulmonary hypertension, as did the IL-1R1 $1^{-/-}$and MyD88 $8^{-/-}$mice (fig. $3 \mathrm{a}$ and $\mathrm{b}$ ). The peak in lung IL-1 $\beta$ was suppressed in mutant mice and in WT mice treated with anakinra, with a partial decrease in lung IL-6 levels (fig. 3c). Accordingly, the levels of lung phosphorylated NF- $\mathrm{B}$ p65, which increased markedly during hypoxia in WT mice, were reduced in IL-1R1 ${ }^{-1-}$ and $\mathrm{MyD} 88^{-/-}$mice, as well as in WT mice treated with anakinra after 3 weeks of hypoxia (online supplementary fig. S3). In contrast, the increased levels of downstream inflammasome components, including ASCs (apoptosis-associated speck-like protein containing a CARD), IL-18 and caspase-1, remained elevated in $\mathrm{IL}-1 \mathrm{R} 1^{-/-}$and $\mathrm{MyD} 88^{-/-}$mice compared to WT mice (online supplementary fig. S3A and B).

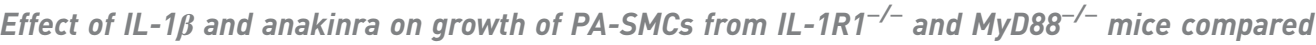 to control WT mice}

Cultured PA-SMCs from normoxic WT mice exhibited strong immunostaining for IL-1R1 and MyD88 (fig. 4a). IL-1 $\beta$ treatment of PA-SMCs from WT mice stimulated cell growth in a dose-dependent manner (fig. 4b) and this effect was suppressed by anakinra (fig. 4c and online supplementary fig. S4). Similar results were observed with human PA-SMCs (online supplementary fig. S5A). IL-1 $\beta$ had no effect on

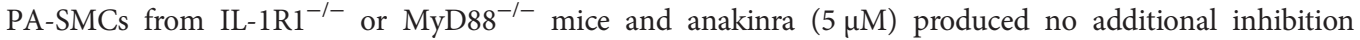
(fig. 4d). The growth-promoting effect of platelet-derived growth factor was unchanged in PA-SMCs from $\mathrm{IL}-1 \mathrm{R} 1^{-/-}$or MyD $88^{-l-}$ mice and unaffected by anakinra (fig. $4 \mathrm{~d}$ and e).

IL-1R1/MyD88 pathway activation persisted in PA-SMCs from mice exposed to chronic hypoxia (fig. 5a). Accordingly, PA-SMCs from chronically hypoxic mice showed increased growth compared to those from control mice, but this increase was not abolished by anakinra (fig. 5b). As expected, anakinra suppressed the activation of NF- $\kappa B$ induced by PA-SMC treatment with IL-1 $\beta$. No changes were seen in ASC, IL-18 and caspase-1 protein levels (online supplementary fig. S6).

\section{Contribution of macrophages to pulmonary hypertension development via the IL-1R1/MyD88 pathway}

Double immunofluorescence staining with F4/80 and IL-1R1 or MyD88 revealed perivascular IL-1R1- and MyD88-stained macrophages in lungs from hypoxic mice, whereas staining was very faint in normoxic mice (fig. $6 \mathrm{a}$ and $\mathrm{b}$ ). The number of perivascular macrophages did not increase from normoxia to hypoxia in hypoxic IL-1R1 $1^{-/-}$or MyD88 ${ }^{-/-}$mice or in anakinra-treated WT mice (fig. 6c).

To further explore the role of IL-1R1/MyD88 signalling in macrophages, we induced hypoxic pulmonary hypertension in transgenic mice with $M y D 88$ gene deletion confined to the myeloid lineage (M.lys-Cre ${\mathrm{MyD} 88^{\mathrm{fl} / \mathrm{fl}} \text { mice), which were compared to MyD88 }}^{-/-}$and WT mice. After 21 days of hypoxia exposure, pulmonary hypertension severity was reduced in M.lys-Cre MyD88 ${ }^{\mathrm{fl} / \mathrm{fl}}$ mice compared to control WT

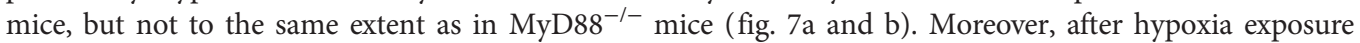
the number of macrophages surrounding pulmonary vessels was smaller in M.lys-Cre MyD88 ${ }^{\mathrm{f} / \mathrm{fl}}$ mice than in WT mice, but higher than in MyD88 $8^{-1-}$ mice (fig. 7c).

\section{Macrophages induced proliferation of PA-SMCs via the IL-1ß/IL-1R1/MyD88 pathway}

We assessed the effects of conditioned medium from bone marrow-derived cultured macrophages on PA-SMC growth. Conditioned media from M0 macrophages induced slight PA-SMC proliferation, with no difference between cells from WT and M.lys-Cre MyD88 ${ }^{\mathrm{fl} / \mathrm{ll}}$ mice and no effects of anakinra (fig. $7 \mathrm{~d}$ ). Conditioned media from M1 macrophages induced greater PA-SMC growth stimulation than did media from M0 macrophages and this effect was partially inhibited by anakinra or was attenuated when using macrophages from M.lys-Cre MyD88 ${ }^{\mathrm{fl} / \mathrm{fl}}$ mice. Finally, M2 macrophage-conditioned media from WT mice induced stronger PA-SMC proliferation compared to media conditioned by M0 or M1 macrophages. This stimulatory effect was not inhibited by anakinra, but was diminished when conditioned media from M.lys-Cre MyD88 ${ }^{\mathrm{fl} / \mathrm{fl}}$ mice were used (fig. $7 \mathrm{~d}$ ). 

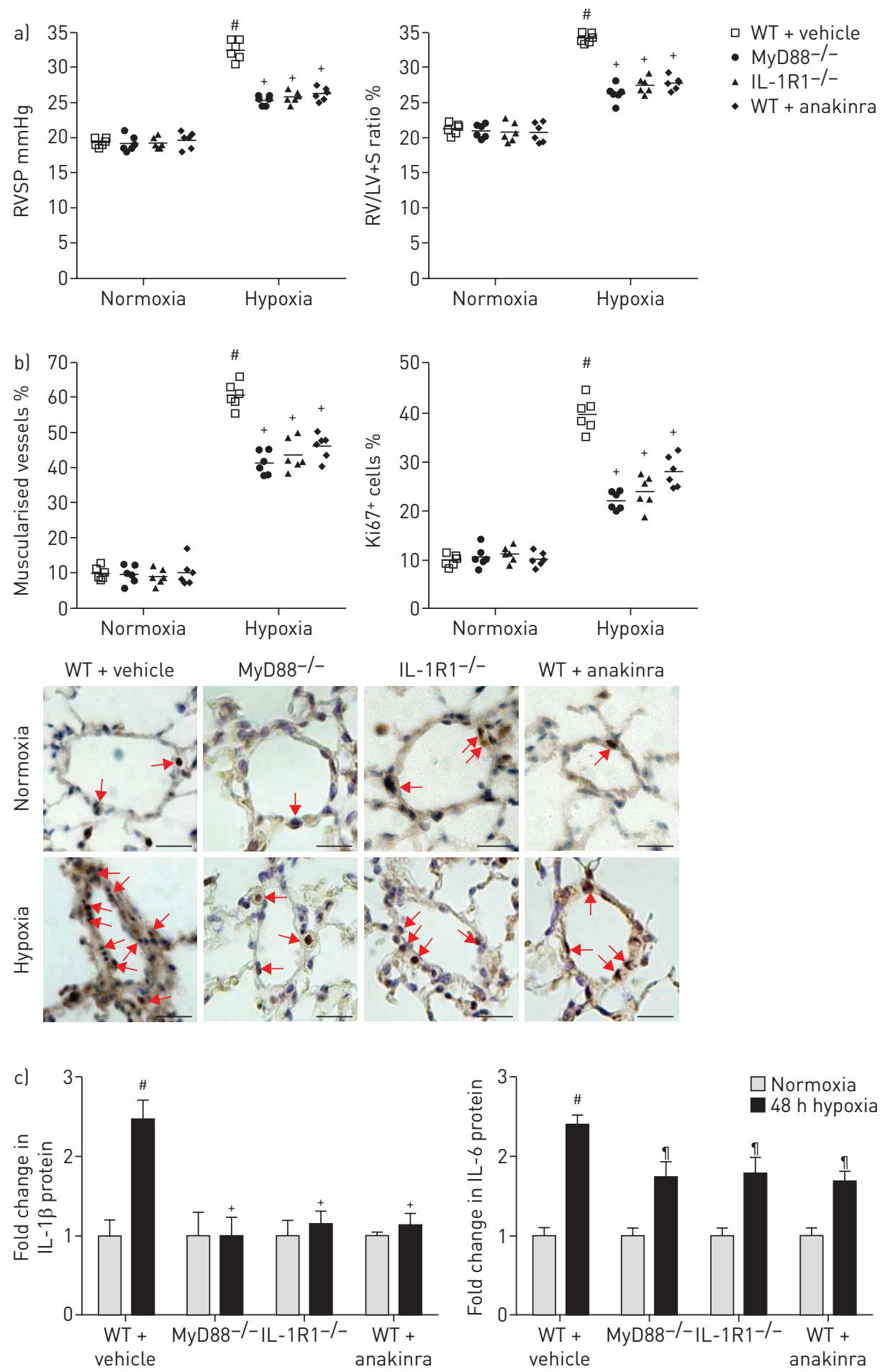

FIGURE 3 MyD88 (myeloid differentiation primary response protein 88) gene deficiency, IL-1R1 (interleukin-1 receptor 1) gene deficiency or anakinra-induced IL-1R1 inhibition similarly abrogated the development of hypoxic pulmonary arterial hypertension (PAH) in mice. a, b) Right ventricular systolic pressure (RVSP) and right ventricular hypertrophy index (right ventricle (RV)/left ventricle (LV) plus septum weight (S)), pulmonary vessel muscularisation and dividing $\mathrm{Ki} 67^{+}$cells in wild-type (WT) mice treated daily with vehicle, MyD88 ${ }^{-/}$ mice, IL-1R $1^{-1-}$ mice and WT mice treated daily with anakinra $\left(20 \mathrm{mg} \cdot \mathrm{kg}^{-1}\right)$, under normoxia and hypoxia (21 days). Representative micrographs of pulmonary vessels stained for Ki67. Red arrows show Ki67 $7^{+}$nuclei. No immunoreactivity was detected in sections incubated with rabbit IgG control and secondary anti-rabbit antibody. Scale bars $=40 \mu \mathrm{m}$. c) Lung IL-1 $\beta$ and IL-6 protein levels measured using ELISA after $48 \mathrm{~h}$ of hypoxia exposure. Data are presented as mean \pm SEM of six animals. ${ }^{\#}: p<0.005$ compared with values in control mice exposed to normoxia; ${ }^{\uparrow}: p<0.0166,{ }^{+}: p<0.0033$ compared with values in control mice exposed to hypoxia. 
a)

$\alpha-S M A$

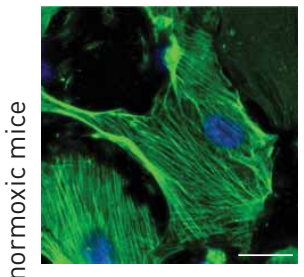

$\alpha-S M A$

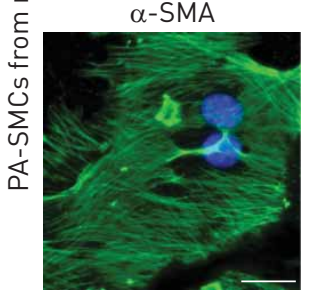

IL-1R1

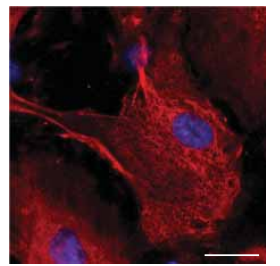

MyD88

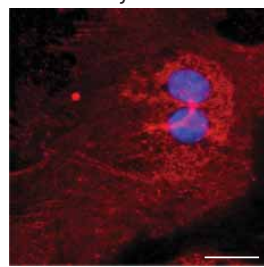

Merge

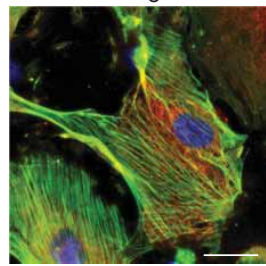

Merge



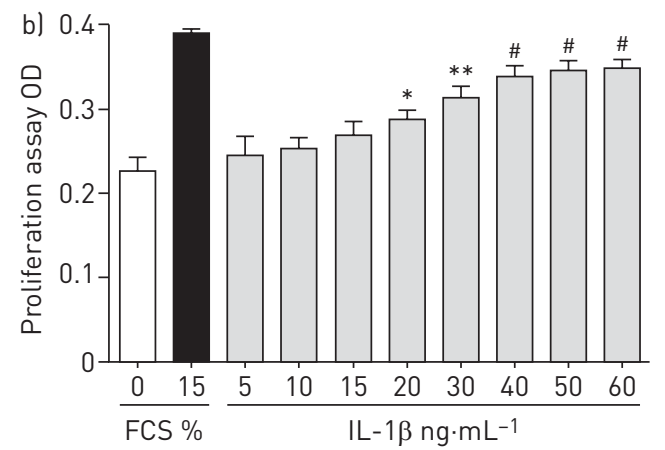


FIGURE 4 Effect of interleukin-1 receptor (IL-1R)1 activation by IL-1 $\beta$ stimulation on proliferation of mouse pulmonary artery smooth muscle cells (PA-SMCs). a) Representative micrographs of PA-SMCs from control normoxic mice. IL-1R1 or MyD88 (red), $\alpha$-smooth muscle actin (SMA) (green) and Hoechst for nucleus staining (blue). No immunoreactivity was detected in sections incubated with rabbit IgG control and secondary anti-rabbit antibody. Scale bars=50 $\mu \mathrm{m}$. b) Dose-response curve of the effect of IL-1 $1 \beta$ on mouse PA-SMC proliferation $\left(5-60 \mathrm{ng} \cdot \mathrm{mL}^{-1}\right)$. Data are presented as mean \pm SEM of 12-16 values from at least two different experiments. OD: optical density; FCS: fetal calf serum. ${ }^{*}$ : $p<0.05 ;{ }^{* *}: p<0.01$; ${ }^{\#}: p<0.005$ compared to non-stimulated cells. c) Dose-response curve of the effect of anakinra (0.01-100 $\mu \mathrm{M})$ on mouse PA-SMC proliferation induced by IL-1 $\beta\left(50 \mathrm{ng} \cdot \mathrm{mL}^{-1}\right)$. Data are presented as mean \pm SEM of $12-16$ values from at least two different experiments. ${ }^{*}: \mathrm{p}<0.05 ;{ }^{* *}$ : $\mathrm{p}<0.01 ;{ }^{\#}$ : $\mathrm{p}<0.005$ compared to cells stimulated with IL-1 $\beta$ alone.

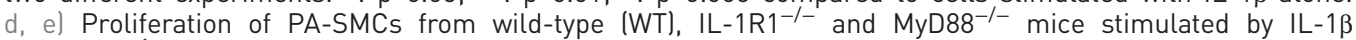
$\left(50 \mathrm{ng} \cdot \mathrm{mL}^{-1}\right)$ or $15 \%$ FCS with or without anakinra $(5 \mu \mathrm{M})$. Data are presented as mean \pm SEM of $18-22$ values from at least three different experiments. ${ }^{\#}$ : $p<0.005$ compared to control cells.

\section{Effects of anakinra on the progression of monocrotaline-induced pulmonary hypertension in rats}

We assessed the potential curative effects of anakinra in rats with monocrotaline-induced pulmonary hypertension. Rats examined 21 days after monocrotaline administration had severe pulmonary hypertension with marked increases in pulmonary arterial pressure (PAP), RV hypertrophy and pulmonary artery muscularisation compared with control rats given saline instead of monocrotaline (fig. 8a). Monocrotaline-treated rats given vehicle from day 21 to day 42 showed further increases in PAP, RV 

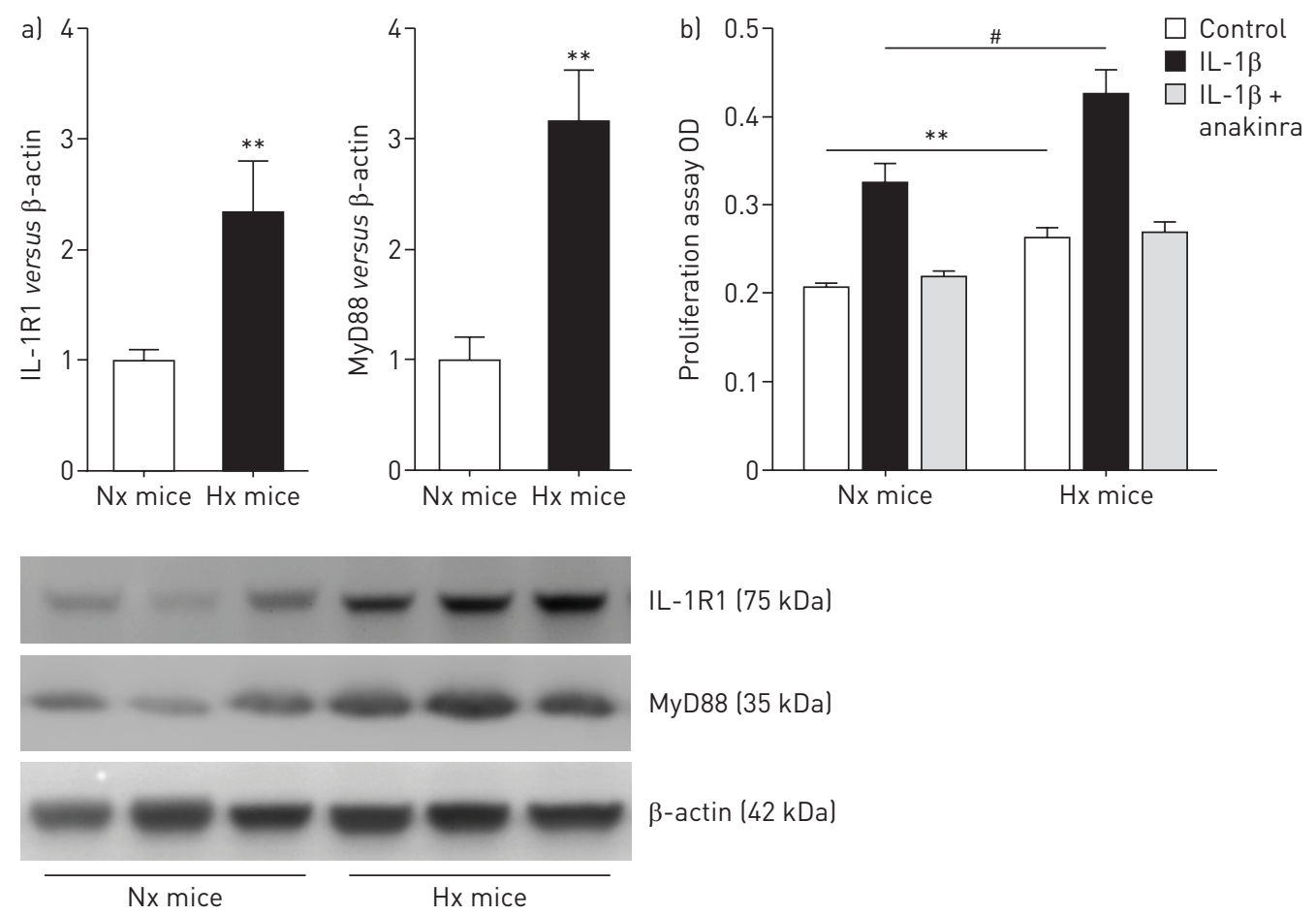

FIGURE 5 Increased expression of the interleukin-1 receptor (IL-1R)1/myeloid differentiation primary response protein 88 (MyD88) pathway and proliferation of pulmonary artery smooth muscle cells (PA-SMCs) from mice exposed to hypoxia. a) IL-1R1 and MyD88 protein levels measured using Western blotting in PA-SMCs from normoxic $(\mathrm{Nx})$ mice or hypoxic $(\mathrm{Hx})$ mice. Data are presented as mean \pm SEM protein levels in PA-SMCs from seven mice. b) Proliferation of PA-SMCs from normoxic or hypoxic mice, stimulated by IL-1 $\beta$ (50 $\mathrm{ng} \cdot \mathrm{mL}^{-1}$ ) with or without anakinra $(5 \mu \mathrm{M})$. Data are presented as mean \pm SEM of 18-22 values from at least three different experiments. OD: optical density. ${ }^{* *}: p<0.01 ;{ }^{\#}: p<0.005$.

hypertrophy and pulmonary vessel wall thickness. In contrast, those given daily anakinra treatment $\left(20 \mathrm{mg} \cdot \mathrm{kg}^{-1}\right)$ from day 21 to 42 showed marked decreases in PAP, RV hypertrophy, number of muscularised pulmonary vessels and pulmonary arterial wall thickness compared with vehicle-treated monocrotaline rats (fig. 8a). Monocrotaline-induced pulmonary hypertension was associated with time-dependent increases in lung IL-1R1 and MyD88 protein levels, together with activation of NF- $\mathrm{KB}$ (fig. 8b) and parallel changes in lung IL-1 $\beta$ and IL-6 mRNA levels (fig. 8c). Of note, anakinra treatment reduced lung NF- $\kappa \mathrm{B}$ activation and, subsequently, lung IL-1 $\beta$ and IL-6 mRNA levels (online supplementary fig. S7).

\section{Discussion}

The present results show that the pulmonary vessel remodelling and inflammation characteristic of pulmonary hypertension development require IL-1R1/MyD88 signalling. Both IL-1R1 and MyD88 were markedly overexpressed in pulmonary vessels from patients with iPAH. In mice exposed to chronic hypoxia, the production of IL-1 $\beta$ and the expression of IL-1R1 and MyD88 preceded the development of pulmonary hypertension. Our finding that $\mathrm{IL}-1 \mathrm{R} 1^{-/-}$and $\mathrm{MyD}^{-/-}$mice were similarly protected against pulmonary hypertension development identified IL-1R1 as a major player in the pathogenesis of pulmonary hypertension which affects both PA-SMC proliferation and macrophage recruitment. The only partial protection of M.lys-Cre MyD88 ${ }^{\mathrm{f} / \mathrm{fl}}$ against pulmonary hypertension indicates that the IL-1ß/IL-1R1 effect on pulmonary hypertension is mediated in part by macrophage activation. Together with the finding that the IL-1R antagonist anakinra also partially reversed established pulmonary hypertension, these results suggest that pharmacological interventions targeting the IL-1 $/$ IL-1R1 pathway may hold promise for treating human PAH.

We focused on the potential role for the IL-1R1/MyD88 pathway in pulmonary hypertension, based on its strong involvement in innate immunity [15]. IL-1 $\beta$ is a major pro-inflammatory cytokine whose expression, maturation and secretion are dependent on the complex processes of innate immunity $[9,11]$. We found an early rise in IL-1 $\beta$ levels upon hypoxia exposure, together with increases in IL-1R1, MyD88, NF- $\kappa$ B and IL-6. The early and transient elevations in IL- $1 \beta, N F-\kappa B$ and IL- 6 are consistent with global activation of the innate immune system, responsible for the initiation of inflammation at the early phase of hypoxia exposure [8]. A major finding is that overexpression of both IL-1R1 and MyD88 was tightly associated with pulmonary vessel remodelling and pulmonary hypertension, as demonstrated in patients with iPAH and in our two murine 
a)
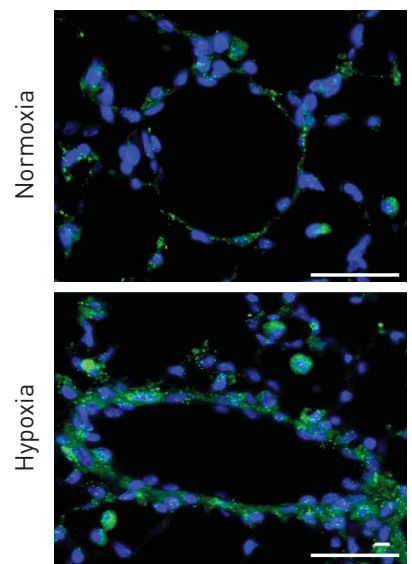

b)
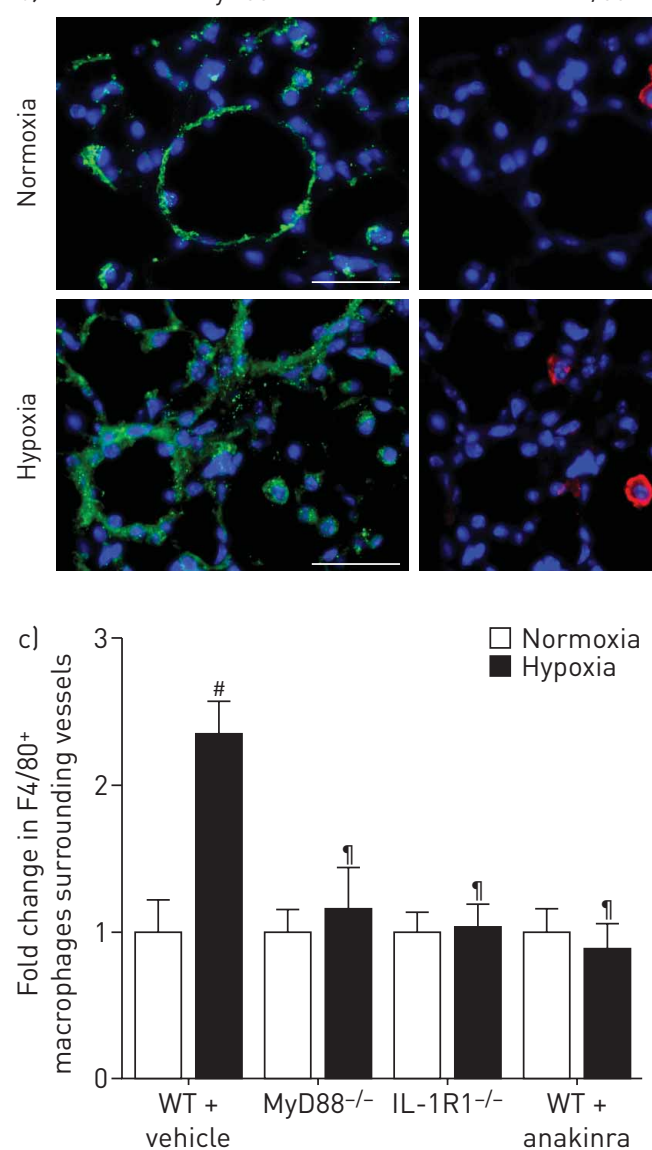

$\mathrm{F} 4 / 80$
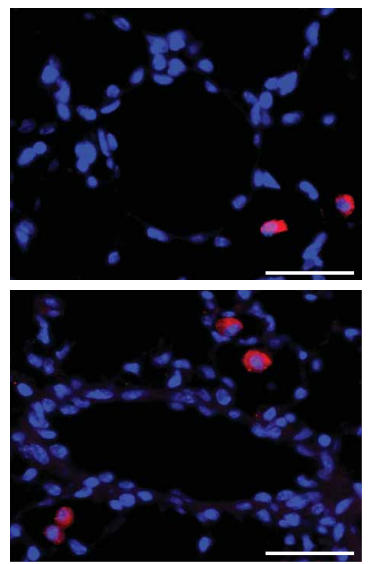

$\mathrm{F} 4 / 80$

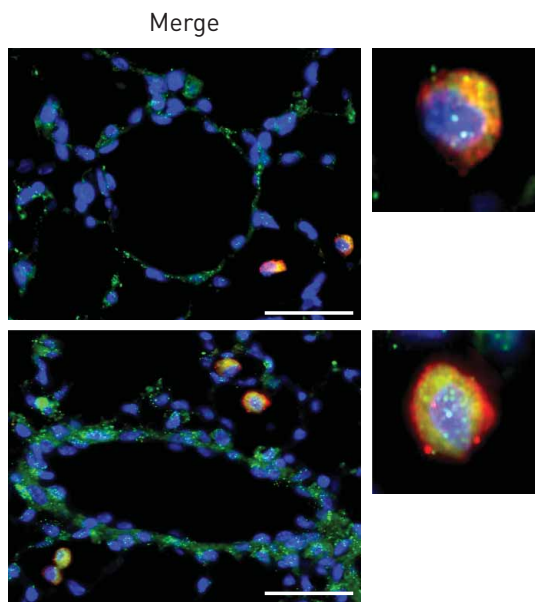

Merge
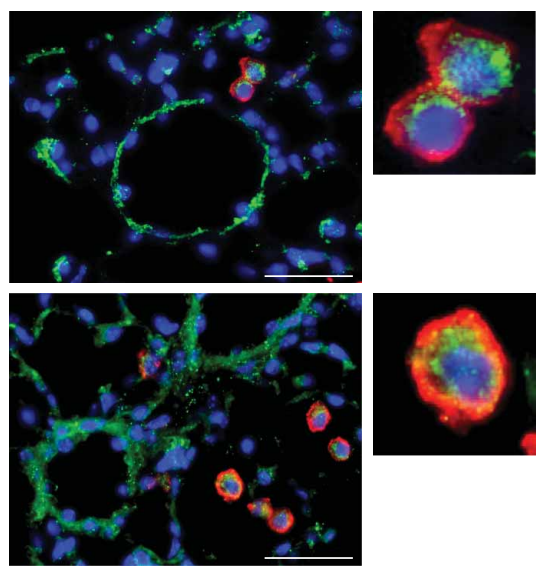
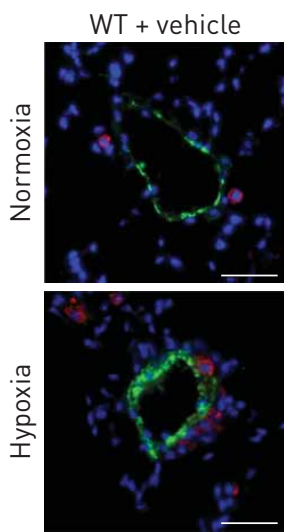
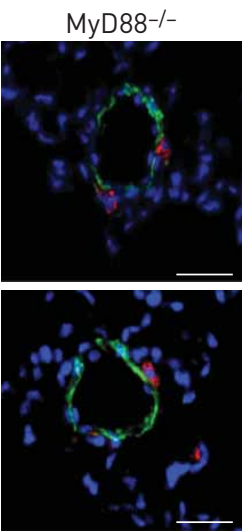

IL-1R1-/-
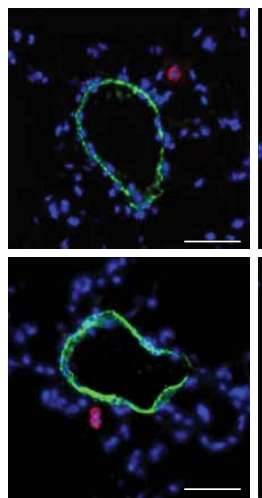

WT + anakinra
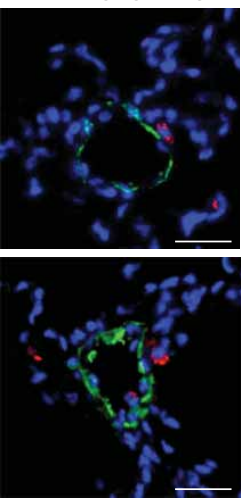

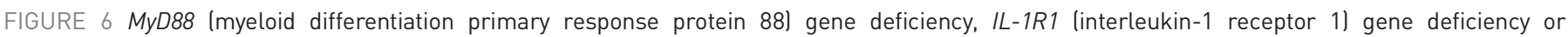
anakinra-induced IL-1R1 inhibition similarly reduced the perivascular macrophage accumulation observed in murine hypoxia-induced pulmonary arterial hypertension. a, b) IL-1R1 and MyD88 are expressed in macrophages stained with F4/80. Lung sections from wild-type (WT) mice under normoxia and after 21 days of hypoxia were stained for IL-1R1 or MyD88 (green) and F4/80 (red). Nuclei were stained with Hoechst dye (blue). c) Macrophage counts surrounding small pulmonary vessels. Vessels are detected using $\alpha$-smooth muscle actin (SMA) staining. The graph depicts the fold change in perivascular $\mathrm{F} 4 / 80^{+}$macrophages between normoxia and hypoxia. The micrographs show representative staining of macrophages surrounding lung vessels in WT mice treated daily with vehicle, MyD88 ${ }^{-/}$mice, IL-1R $1^{-/-}$mice and WT mice treated daily with anakinra (20 mg.kg ${ }^{-1}$ ), during 21 days of hypoxia. No positive immunoreactivity was detected in sections incubated with control IgG followed by secondary anti-rabbit or anti-rat antibody. Scale bars $=30 \mu \mathrm{m} .{ }^{\#}$ : $p<0.005$ compared to control WT normoxic mice; ${ }^{\text {१: }}$ p<0.0033 compared to control WT hypoxic mice.

pulmonary hypertension models, i.e. mice exposed to hypoxia and SM22-5HTT ${ }^{+}$mice. Moreover, IL-1R1 and MyD88 were strongly expressed by PA-SMCs as well as by lung macrophages. These results confirm that both of these major transduction elements are expressed in the lung, not only by cells of myeloid lineage, but also by constitutive vascular cells, whose proliferation underlies the pulmonary vessel remodelling process. 

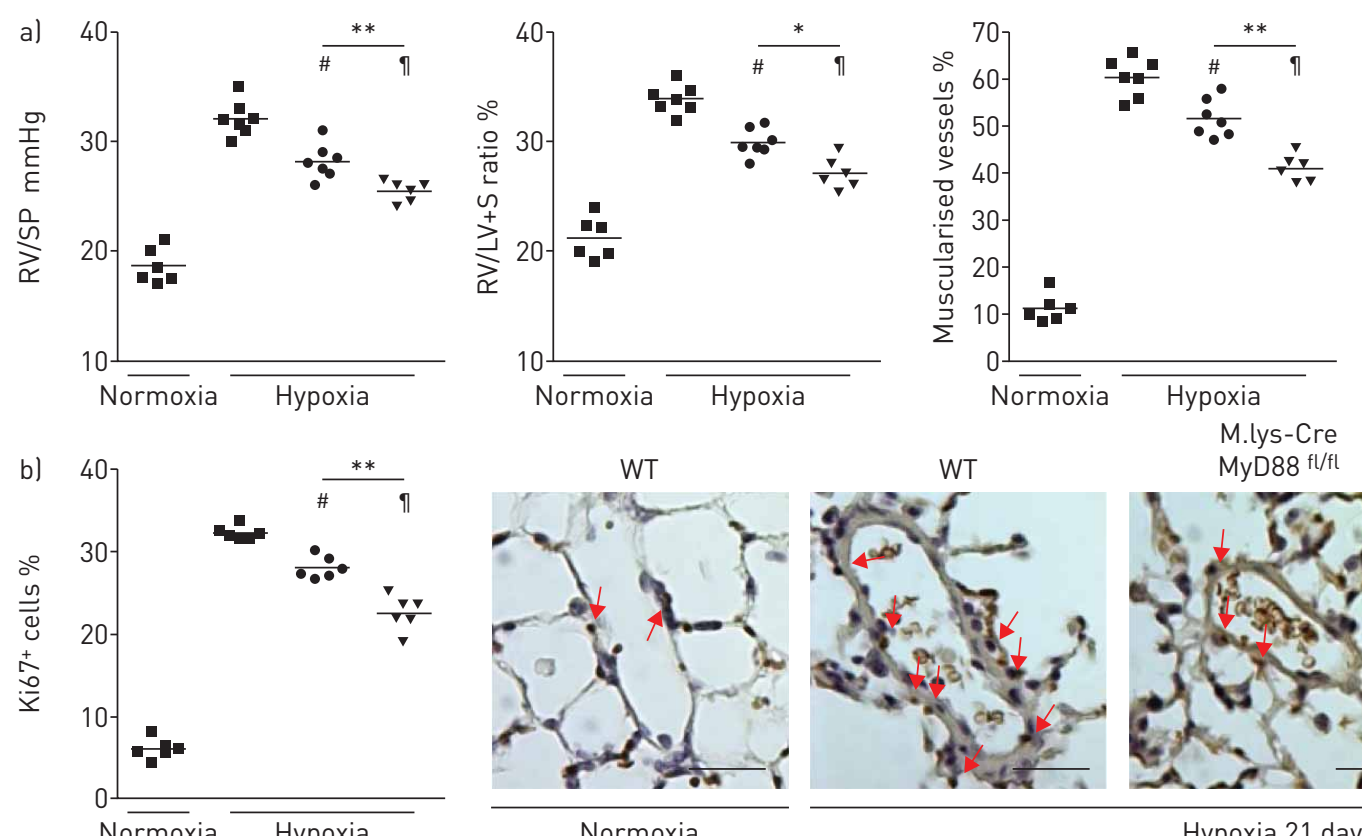

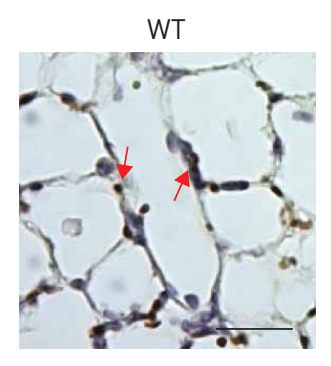

Normoxia



MyD88 fl/fl



Hypoxia 21 days
- WT

- M.lys-Cre MyD88fl/fl

$\nabla \mathrm{MyD} 88^{-/-}$

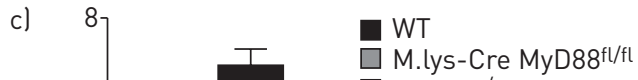

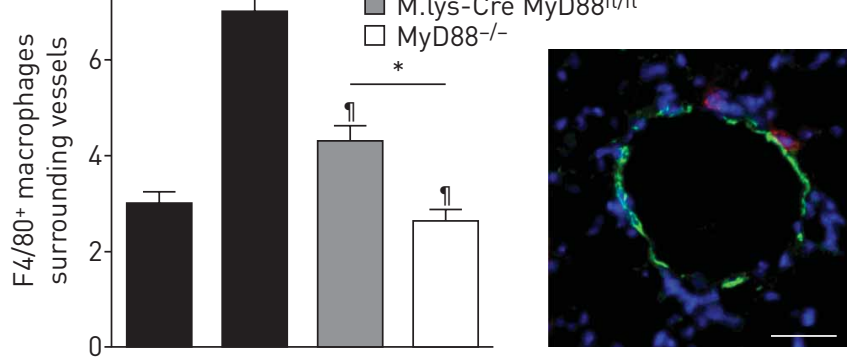

Normoxia

Hypoxia

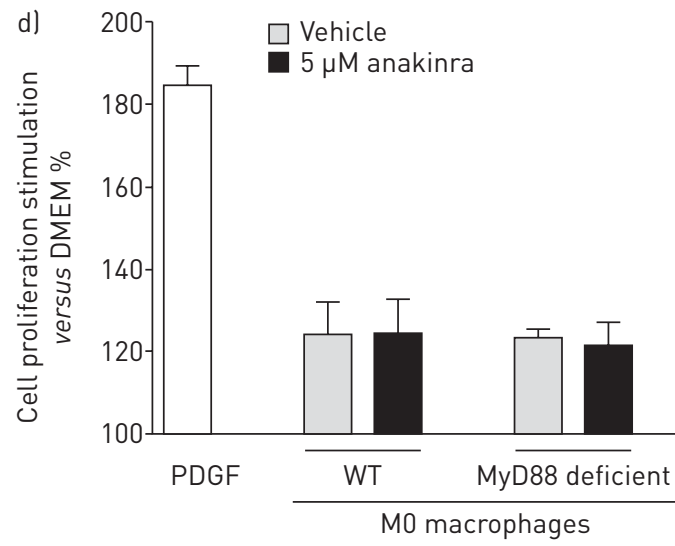

$\square$ Vehicle

$5 \mu \mathrm{M}$ anakinra

Normoxia WT Hypoxia WT

Hypoxia WT

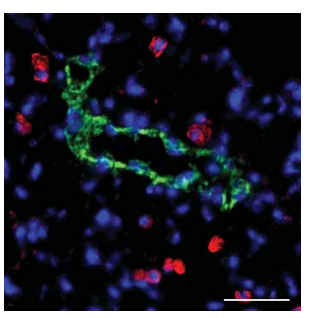

(1)

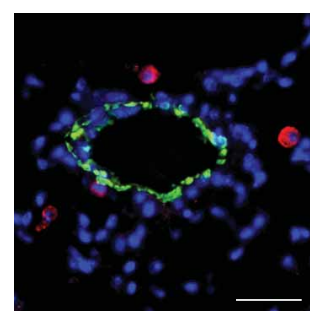

Hypoxia M.LysCre MyD88fl/fl

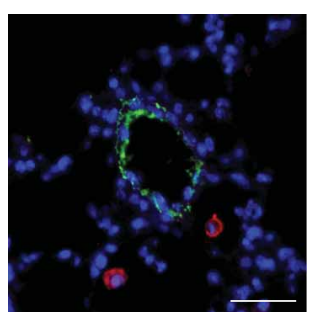

Hypoxia MyD88-/-

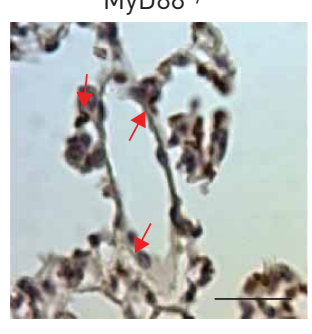



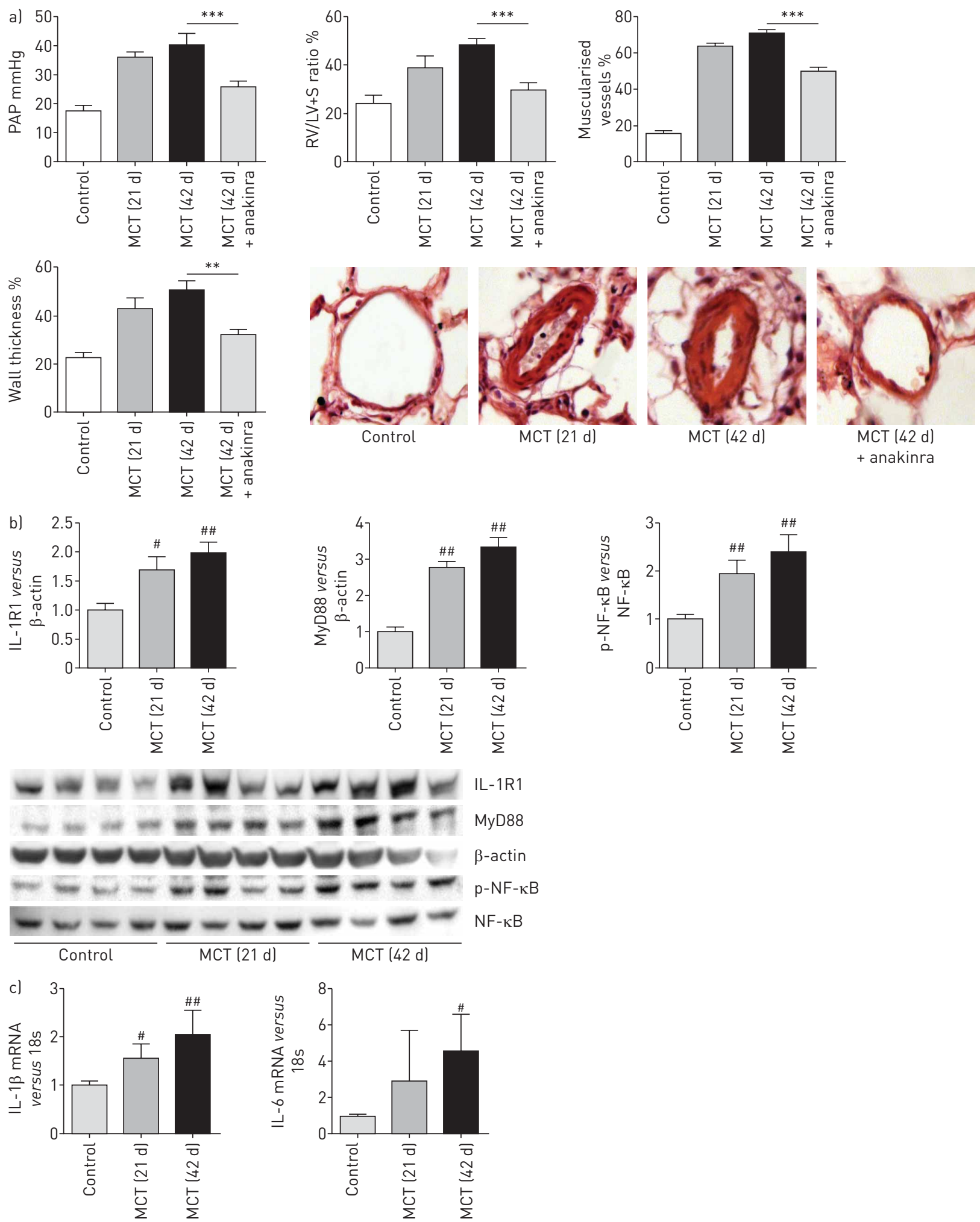

FIGURE 8 Anakinra reversed the progression of pulmonary hypertension induced in rats by monocrotaline injection. a) Pulmonary arterial pressure (PAP) and right ventricular hypertrophy index (right ventricle (RV)/left ventricle (LV) plus septum weight (S)) in rats studied 21 days (d) or $42 \mathrm{~d}$ after administration of monocrotaline (MCT) or saline (controls). Anakinra (20 mg $\mathrm{kg}^{-1}$ per day) or vehicle was given intraperitoneally from day 21 to 42 . Pulmonary vascular remodelling: muscularisation of pulmonary vessels, reported as the percentages of non-muscularised or fully muscularised distal vessels and pulmonary artery wall thickness from rats on days 21 and 42 after saline (controls) or MCT administration. Representative micrographs of pulmonary vessels are shown. Each value is the mean \pm SEM of 10 independent determinations. Data are presented as mean \pm SEM of seven or eight animals. ${ }^{* *}: \mathrm{p}<0.01 ;{ }^{* * *}: \mathrm{p}<0.001$. b) Lung levels of interleukin-1 receptor (IL-1R)1 protein, myeloid differentiation primary response


Western blotting before and at different time points after MCT administration. ${ }^{\#}$ : $p<0.025,{ }^{\# \#}$ : $p<0.005$, compared with control values. c) Lung levels of IL-1 $\beta$ and IL- 6 mRNA at the same time points. Data are presented as mean \pm SEM of six animals. ${ }^{\#}: p<0.025,{ }^{\# \#}$ : $p<0.005$, compared with control values. 
We found that $I L-1 R 1$ or $M y D 88$ gene deletion and/or pharmacological inactivation of IL-1R1 protected mice against hypoxic pulmonary hypertension and partially reversed pulmonary hypertension in $\mathrm{SM}_{22}-5 \mathrm{HTT}^{+}$mice. Of note, protection against hypoxic pulmonary hypertension was of similar magnitude in $\mathrm{MyD} 88^{-/-}$mice, IL-1R1 $1^{-1-}$ mice and WT mice treated with anakinra. This indicates that the protection against pulmonary hypertension afforded by $M y D 88$ deletion was mainly due to inactivation of the IL-1R1/ MyD88 pathway, without any combined effects of the TLR/MyD88 pathway. This finding does not conflict with previous reports that TLR-4 deletion in mice confers some protection against pulmonary hypertension $[23,24]$. Indeed, MyD88 as an adaptor protein is not mandatory for TLR-4 signal transduction to occur [10]. Moreover, we found that high mobility group box-1-induced TLR-4 stimulation in PA-SMCs was not associated with a strong effect on cell growth, as previously reported [23]. Another interesting point is that the early increase in IL- $1 \beta$ in response to hypoxia was completely suppressed in MyD88 $8^{-/-}$mice, IL- $1 \mathrm{R} 1^{-/-}$ mice and WT mice treated with the IL-1R1 inhibitor, which also exhibited a marked reduction in lung NF- $\kappa B$. This finding is consistent with the ability of IL- $1 \beta$ to induce its own synthesis via IL-1R1/ MyD88-mediated activation of NF- $\mathrm{B}[15,30]$. In contrast, no changes were observed in downstream molecular components of the inflammasome in $\mathrm{MyD} 88^{-/-}$mice or IL-1R1 ${ }^{-/-}$mice.

Protection against pulmonary hypertension was associated with decreases in distal PA muscularisation and with a decrease in perivascular macrophage counts. We evaluated the potential influence of IL-1 $\beta$ on PA-SMC proliferation. In keeping with previous results reported by our group and others [20-22], IL-1 $\beta$ $\left(50 \mathrm{ng} \cdot \mathrm{mL}^{-1}\right)$ strongly enhanced the growth of cultured PA-SMCs. As expected, this stimulatory effect of IL- $1 \beta$ was suppressed by anakinra and was not observed in PA-SMCs from either IL- $1 \mathrm{R} 1^{-/-}$or MyD88 $8^{-/-}$ mice. Thus, these in vitro results are consistent with a direct effect on PA-SMCs mediated by IL-1R1/ MyD88 signalling. In addition, IL-1R1 and MyD88 expression was increased in PA-SMCs from chronically hypoxic mice, with a stronger growth-promoting effect of IL-1 $\beta$ in PA-SMCs from chronically hypoxic mice than from normoxic controls. However, anakinra failed to completely reverse the increased growth rate of cells from chronically hypoxic mice.

In our study, perivascular macrophage counts were diminished in anakinra-treated hypoxic mice and in hypoxic IL-1R1 ${ }^{-/-}$or ${\mathrm{MyD} 88^{-/}}^{-}$mice, compared to their respective controls. The mechanisms underlying the decrease in macrophage counts may involve specific inactivation of the IL-1R1 on macrophages, or on other cell types including endothelial cells, which express adhesion molecules for monocytes [31, 32]. We therefore compared hypoxic $\mathrm{MyD} 8^{-1-}$ mice with mice whose $M y D 88$ gene had been deleted only in macrophages (M.lys-Cre MyD88 $8^{\mathrm{fl} / \mathrm{fl}}$ mice). We found that M.lys-Cre MyD88 ${ }^{\mathrm{fl} / \mathrm{fl}}$ mice were protected against pulmonary hypertension, but to a lesser extent than $\mathrm{MyD} 8^{-/-}$mice, and also showed a smaller decrease in perivascular macrophage counts. These results indicate that the effects of IL-1R1 inactivation were related in part to the perivascular macrophages. That global deletion was more efficient on pulmonary hypertension than macrophage-specific deletion of MyD88 is consistent with a dual effect of IL-1R1, on macrophage migration and activation, as well as on PA-SMC proliferation. To further delineate the role for IL- $1 \beta$ in mediating the effects of macrophages on PA-SMC proliferation, we examined the effects of media conditioned by macrophages from WT and M.lys-Cre MyD88 $8^{\mathrm{fl} / \mathrm{fl}}$ mice, with culture conditions that produced M0, M1 and M2 macrophages. As previously reported [33, 34], we found that conditioned medium from any of these three macrophage types stimulated PA-SMC growth, with greater effects of M2 compared to M1 macrophages, and of M1 compared to M0 macrophages. An effect on PA-SMC growth of macrophage-derived IL-1 $\beta$ was clearly shown with M1 macrophages, since the stimulatory effect of the macrophage medium was reduced by anakinra. No effect of anakinra was found using conditioned medium from M2 macrophages. However, MyD88 deficiency reduced the stimulatory effect of M2 macrophages on PA-SMC growth, supporting an important role for MyD88 in macrophage activation and subsequent mitogenic-factor release. Taken together, these studies support a role for the IL-1R1/MyD88 pathway in mediating macrophage recruitment around pulmonary vessels and macrophage activation responsible for the release of PA-SMC mitogens, including IL-1 $\beta$ among the factors released by M1 macrophages.

By focusing on the IL-1R1/MyD88 pathway, we investigated a primary mechanism involved in the innate immune response that occurs at an early phase of pulmonary hypertension development. That genetic or pharmacological IL-1R1/MyD88 pathway inactivation may prevent the development of pulmonary hypertension is consistent with a key contribution of inflammation to the initiation of pulmonary hypertension. In addition, our results indicate that pharmacological intervention targeting this pathway at the stage of established pulmonary hypertension can partially reverse pulmonary hypertension. In rats with established monocrotaline-induced pulmonary hypertension, daily anakinra treatment started 3 weeks after the monocrotaline injection produced large decreases in PAP, RV hypertrophy, number of muscularised pulmonary vessels and pulmonary arterial wall thickness compared with monocrotaline-injected rats given vehicle instead of anakinra. Thus, anakinra reversed the progression of pulmonary hypertension induced in rats by monocrotaline injection to an extent that appeared greater than in SM22-5HTT ${ }^{+}$mice. Moreover, 
increased expression of IL1R1 and Myd88 was found in lungs from monocrotaline-treated rats, together with increased expression of IL-1 $\beta$, as also reported in previous studies [35]. These findings, together with the strong inhibitory effect of anakinra on NF- $\kappa \mathrm{B}$ activation and on IL- $1 \beta$ and IL-6 expression, are consistent with the general concept of a major inflammatory component in monocrotaline-induced pulmonary hypertension [25], and establish the pivotal importance of the IL-1R1/MyD88 pathway in pulmonary hypertension progression, even at the stage of advanced pulmonary hypertension. Our observation of prominent MyD88 overexpression in PA-SMCs and macrophages from patients with iPAH strongly supports the concept that targeting the IL-1R1/MyD88 pathway may provide clinical benefits to patients with PAH. Consistent with this possibility, an improvement in PAH was recently reported in a patient who received anakinra therapy to treat adult-onset Still's disease [26]. Further studies are therefore warranted to evaluate whether targeting the IL-1R1/MyD88 pathway constitutes a valid treatment option for patients with PAH.

\section{Acknowledgements}

We thank Richard Souktani, Xavier Decrouy and Christelle Micheli from the IMRB platform facilities (INSERM U955, Créteil, France); and Florence Savigny (UMR7355, Orleans, France) for her technical assistance.

\section{References}

1 Rabinovitch M, Guignabert C, Humbert M, et al. Inflammation and immunity in the pathogenesis of pulmonary arterial hypertension. Circ Res 2014; 115: 165-175.

2 Perros F, Dorfmüller P, Souza R, et al. Dendritic cell recruitment in lesions of human and experimental pulmonary hypertension. Eur Respir J 2007; 29: 462-468.

3 Savai R, Pullamsetti SS, Kolbe J, et al. Immune and inflammatory cell involvement in the pathology of idiopathic pulmonary arterial hypertension. Am J Respir Crit Care Med 2012; 186: 897-908.

4 Amsellem V, Lipskaia L, Abid S, et al. CCR5 as a treatment target in pulmonary arterial hypertension. Circulation 2014; 130: 880-891.

5 Morrell NW, Adnot S, Archer SL, et al. Cellular and molecular basis of pulmonary arterial hypertension. J Am Coll Cardiol 2009; 54: S20-S31.

6 Price LC, Wort SJ, Perros F, et al. Inflammation in pulmonary arterial hypertension. Chest 2012; 141: 210-221.

7 Hassoun PM, Mouthon L, Barberà JA, et al. Inflammation, growth factors, and pulmonary vascular remodeling. J Am Coll Cardiol 2009; 54: S10-S19.

8 Vergadi E, Chang MS, Lee C, et al. Early macrophage recruitment and alternative activation are critical for the later development of hypoxia-induced pulmonary hypertension. Circulation 2011; 123: 1986-1995.

9 Schroder K, Tschopp J. The inflammasomes. Cell 2010; 140: 821-832.

10 Lin Q, Li M, Fang D, et al. The essential roles of Toll-like receptor signaling pathways in sterile inflammatory diseases. Int Immunopharmacol 2011; 11: 1422-1432.

11 Martinon F, Burns K, Tschopp J. The inflammasome: a molecular platform triggering activation of inflammatory caspases and processing of proIL- $\beta$. Mol Cell 2002; 10: 417-426.

12 Dinarello CA. A clinical perspective of IL-1 $\beta$ as the gatekeeper of inflammation. Eur J Immunol 2011; 41: 1203-1217.

13 Dinarello CA. Interleukin-1. Cytokine Growth Factor Rev 1997; 8: 253-265.

14 Arend WP, Guthridge CJ. Biological role of interleukin 1 receptor antagonist isoforms. Ann Rheum Dis 2000; 59: Suppl. 1, i60-i64.

15 Dinarello CA. Immunological and inflammatory functions of the interleukin-1 family. Ann Rev Immunol 2009; 27: 519-550.

16 Warner N, Núñez G. MyD88: a critical adaptor protein in innate immunity signal transduction. J Immunol 2013; 190: 3-4.

17 Muzio M, Ni J, Feng P, et al. IRAK (Pelle) family member IRAK-2 and MyD88 as proximal mediators of IL-1 signaling. Science 1997; 278: 1612-1615.

18 Dunne A, O'Neill LA. The interleukin-1 receptor/Toll-like receptor superfamily: signal transduction during inflammation and host defense. Sci STKE 2003; 2003: re3.

19 O'Neill LA. The interleukin-1 receptor/Toll-like receptor superfamily: 10 years of progress. Immunol Rev 2008; 226: $10-18$.

20 Houssaini A, Abid S, Mouraret N, et al. Rapamycin reverses pulmonary artery smooth muscle cell proliferation in pulmonary hypertension. Am J Respir Cell Mol Biol 2013; 48: 568-577.

$21 \mathrm{Li} \mathrm{P,} \mathrm{Li} \mathrm{YL,} \mathrm{Li} \mathrm{ZY,} \mathrm{et} \mathrm{al.} \mathrm{Cross} \mathrm{talk} \mathrm{between} \mathrm{vascular} \mathrm{smooth} \mathrm{muscle} \mathrm{cells} \mathrm{and} \mathrm{monocytes} \mathrm{through} \mathrm{interleukin-1 \beta /}$ interleukin-18 signaling promotes vein graft thickening. Arterioscler Thromb Vasc Biol 2014; 34: 2001-2011.

22 Liu PL, Liu JT, Kuo HF, et al. Epigallocatechin gallate attenuates proliferation and oxidative stress in human vascular smooth muscle cells induced by interleukin-1 $\beta$ via heme oxygenase-1. Mediators Inflamm 2014; 2014: 523684 .

23 Bauer EM, Shapiro R, Zheng $\mathrm{H}$, et al. High mobility group box 1 contributes to the pathogenesis of experimental pulmonary hypertension via activation of Toll-like receptor 4. Mol Med 2013; 18: 1509-1518.

24 Bauer EM, Chanthaphavong RS, Sodhi CP, et al. Genetic deletion of toll-like receptor 4 on platelets attenuates experimental pulmonary hypertension. Circ Res 2014; 114: 1596-1600.

25 Voelkel NF, Tuder RM, Bridges J, et al. Interleukin-1 receptor antagonist treatment reduces pulmonary hypertension generated in rats by monocrotaline. Am J Respir Cell Mol Biol 1994; 11: 664-675.

26 Campos M, Schiopu E. Pulmonary arterial hypertension in adult-onset Still's disease: rapid response to anakinra. Case Rep Rheumatol 2012; 2012: 537613.

27 Labow M, Shuster D, Zetterstrom M, et al. Absence of IL-1 signaling and reduced inflammatory response in IL-1 type I receptor-deficient mice. J Immunol 1997; 159: 2452-2461.

28 Kawai T, Adachi O, Ogawa T, et al. Unresponsiveness of MyD88-deficient mice to endotoxin. Immunity 1999; 11 : 115-122. 
29 Guignabert C, Izikki M, Tu LI, et al. Transgenic mice overexpressing the 5-hydroxytryptamine transporter gene in smooth muscle develop pulmonary hypertension. Circ Res 2006; 98: 1323-1330.

30 Dinarello CA, Ikejima T, Warner SJ, et al. Interleukin 1 induces interleukin 1. I. Induction of circulating interleukin 1 in rabbits in vivo and in human mononuclear cells in vitro. J Immunol 1987; 139: 1902-1910.

31 Zsebo KM, Wypych J, Yuschenkoff VN, et al. Effects of hematopoietin-1 and interleukin 1 activities on early hematopoietic cells of the bone marrow. Blood 1988; 71: 962-968.

32 Zsebo KM, Yuschenkoff VN, Schiffer S, et al. Vascular endothelial cells and granulopoiesis: interleukin-1 stimulates release of G-CSF and GM-CSF. Blood 1988; 71: 99-103.

33 Khallou-Laschet J, Varthaman A, Fornasa G, et al. Macrophage plasticity in experimental atherosclerosis. PloS One 2010; 5: e8852.

34 Zhang H, Downs EC, Lindsey JA, et al. Interactions between the monocyte/macrophage and the vascular smooth muscle cell. Stimulation of mitogenesis by a soluble factor and of prostanoid synthesis by cell-cell contact. Arterioscler Thromb 1993; 13: 220-230.

35 Gillespie MN, Goldblum SE, Cohen DA, et al. Interleukin 1 bioactivity in the lungs of rats with monocrotalineinduced pulmonary hypertension. Proc Soc Exp Biol Med 1988; 187: 26-32. 